Article

\title{
A Novel Route to High-Quality Graphene Quantum Dots by Hydrogen-Assisted Pyrolysis of Silicon Carbide
}

\author{
Na Eun Lee, Sang Yoon Lee, Hyung San Lim, Sung Ho Yoo and Sung Oh Cho * \\ Department of Nuclear and Quantum Engineering, Korea Advanced Institute of Science and \\ Technology (KAIST), Daejeon 34141, Korea; pancy6@kaist.ac.kr (N.E.L.); sangyoonlee@kaist.ac.kr (S.Y.L.); \\ samsterdam@kaist.ac.kr (H.S.L.); nafirst4@kaist.ac.kr (S.H.Y.) \\ * Correspondence: socho@kaist.ac.kr; Tel.: +82-(0)42-350-3823; Fax: +82-(0)42-350-3810
}

Received: 17 January 2020; Accepted: 2 February 2020; Published: 6 February 2020

check for updates

\begin{abstract}
Graphene quantum dots (GQDs) can be highly beneficial in various fields due to their unique properties, such as having an effective charge transfer and quantum confinement. However, defects on GQDs hinder these properties, and only a few studies have reported fabricating high-quality GQDs with high crystallinity and few impurities. In this study, we present a novel yet simple approach to synthesizing high-quality GQDs that involves annealing silicon carbide ( $\mathrm{SiC}$ ) under low vacuum while introducing hydrogen $(\mathrm{H})$ etching gas; no harmful chemicals are required in the process. The fabricated GQDs are composed of a few graphene layers and possess high crystallinity, few defects and high purity, while being free from oxygen functional groups. The edges of the GQDs are hydrogen-terminated. High-quality GQDs form on the etched $\mathrm{SiC}$ when the etching rates of $\mathrm{Si}$ and $\mathrm{C}$ atoms are monitored. The size of the fabricated GQDs and the surface morphology of SiC can be altered by changing the operating conditions. Collectively, a novel route to high-quality GQDs will be highly applicable in fields involving sensors and detectors.
\end{abstract}

Keywords: graphene quantum dots; silicon carbide; hydrogen-assisted pyrolysis; high-quality

\section{Introduction}

Graphene quantum dots (GQDs), composed of few graphene layers with a size less than $30 \mathrm{~nm}$, have attracted research interest due to their unique properties, such as possessing a large surface area, low toxicity and strong and tunable photoluminescence [1-4]. With these advantageous characteristics, GQDs can be used for bioimaging [5,6], biosensing [7], photovoltaics [8,9], drug delivery [10,11] and optoelectronic devices [12,13]. Both top-down and bottom-up approaches have been developed to synthesize GQDs. The top-down approaches include electron-beam lithography [4], chemical oxidation [14,15], electrochemical exfoliation $[7,8,16]$, hydrothermal/solvothermal treatment $[6,17]$ and microwave/ultrasound methods [18-21], all of which have difficulties in precisely controlling the size of the GQDs produced and in reducing the defects of synthesized GQDs [22]. Bottom-up approaches rely on the carbonization of organic precursors [23-27], but these approaches face issues resulting from the involvement of harmful chemicals and the complexity of the synthesis process [22]. Additionally, the basal plane or edges of GQDs synthesized by these methods are passivated by oxygen functional groups such as carboxyl, carbonyl and hydroxyl groups. The characteristics of GQDs, such as having an effective charge transfer and quantum confinement, are hindered by these defects $[4,28]$. Currently, only a few studies have reported fabricating high-quality GQDs; thus producing GQDs that have high crystallinity, few defects and high purity is therefore of great importance as GQDs have many promising applications in fields involving sensors and detectors [4,28]. 
In this study, we present a novel route to fabricating high-quality GQDs that involves hydrogen-assisted pyrolysis of silicon carbide $(\mathrm{SiC})$ without the use of harmful chemicals. The pyrolysis of $\mathrm{SiC}$ has been used widely for the synthesis of epitaxial graphene (EG) $[29,30]$. Generally, EG is synthesized in two completely different environments: either under ultrahigh vacuum (UHV, $<10^{-10}$ Torr $)$ at comparatively low temperature $\left(<1300^{\circ} \mathrm{C}\right)$ or under atmospheric pressure in argon (Ar) gas at relatively high temperature $\left(>1600{ }^{\circ} \mathrm{C}\right)$ [31]. In the UHV environment, irregular pits are formed on the $\mathrm{SiC}$ surface and small graphene clusters (of a few hundreds of nanometers in size) are created on the pitted surface. In comparison, in the Ar atmosphere environment, a uniformly stepped SiC surface is formed and large EG clusters ( $>$ hundreds of $\mu \mathrm{m}$ in size) are synthesized on the stepped surface. Before thermal decomposition, the $\mathrm{SiC}$ surface is treated by hydrogen $(\mathrm{H})$ etching. The $\mathrm{H}$ etching process also plays an important role in determining the morphology of the fabricated EG [32]. In our previous research, we discovered that if a $\mathrm{SiC}$ plate is $\mathrm{H}$ etched under vacuum ( 100 Torr), steps of heights reaching up to $100 \mathrm{~nm}$ could be fabricated [33]. These findings indicate that the morphologies of both the graphene and $\mathrm{SiC}$ surface are significantly affected by the annealing conditions, and particularly the etching rate of $\mathrm{Si}$ and $\mathrm{C}$ atoms on the SiC surface. These results inspired us to develop and propose a novel approach to synthesizing GQDs by annealing SiC under low vacuum while introducing $\mathrm{H}$ etching gas into the vacuum environment. When pyrolyzed under vacuum containing the etching gas, very rapid etching of SiC occurs, converting the surface into a bumpy structure with pits that are a few micrometers deep. On this bumpy surface, an abundance of H-terminated high-quality GQDs is ubiquitously created. Fabricated GQDs have a highly ordered crystalline structure with high purities. The size of the synthesized GQDs can be controlled by adjusting the operating conditions, such as the annealing temperature.

\section{Materials and Methods}

\subsection{Materials}

We purchased $4 \mathrm{H}$ nitrogen-doped $\mathrm{SiC}$ plates with an off-axis angle of $4^{\circ}$ relative to the (0001) basal plane from TankeBlue Co., Ltd. (Beijing, China). Ethanol $\left(\mathrm{C}_{2} \mathrm{H}_{5} \mathrm{OH},>99.9 \%\right)$ was purchased from Merck Chemicals (Darmstadt, Germany).

\subsection{High-Quality GQDs Preparation}

The $4 \mathrm{H}$ nitrogen-doped $\mathrm{SiC}$ plates were ultrasonically cleaned in ethanol and subsequently annealed in an alumina furnace, where a mixed gas comprising argon (Ar, 96 at.\%) and hydrogen $(\mathrm{H}, 4$ at.\%) flowed through. The pressure of the vacuum furnace was changed from 80 160 mTorr by adjusting the flow rate of the mixture gas from 8 to $16 \mathrm{sccm}$. The maximum temperature of the furnace was also modified from $1400 \sim 1500^{\circ} \mathrm{C}$. The heating rate of the furnace to reach the maximum temperature was $5^{\circ} \mathrm{C}$ per min, the maximum temperature was maintained for $30 \mathrm{~min}$ and the cooling rate to reach room temperature was $5^{\circ} \mathrm{C}$ per min. The annealed $\mathrm{SiC}$ samples were sonicated at $80 \mathrm{kHz}$ in $2 \mathrm{~mL}$ of ethanol for $3 \mathrm{~min}$ to detach the synthesized GQDs from the SiC substrates. Subsequently, the solutions of the GQDs were centrifuged at $8000 \mathrm{rpm}$ with 10,000 molecular weight cut-off (MWCO) microfilters to eliminate any large particles that were detached from the substrates.

\subsection{Characterizations}

The surface morphology of the specimens was characterized using a field-emission scanning electron microscope (FESEM, Hitachi S-4800, Hitachi, Tokyo, Japan). The size distribution and lattice spacing of the GQDs were examined using a transmission electron microscope (TEM) and high-resolution transmission electron microscope (HRTEM; Tecnai G ${ }^{2}$ F30 S-Twin, FEI, Hillsboro, OR, USA). The thickness of the GQDs was determined using an atomic force microscope (AFM; XE70, Park systems, Suwon, Korea). The Raman spectra were measured using a Raman spectrophotometer (Resolution of $0.75 \mathrm{~cm}^{-1}$, Horiba Jobin Yvon, Kyoto, Japan) with a $514 \mathrm{~nm}$ laser source with a spot 
size of $2 \mu \mathrm{m}$. The chemical composition of the GQDs was analyzed by a Fourier transform infrared (FT-IR) spectrometer (Nicolet iS50, Thermo Fisher Scientific Instrument, Waltham, MA, USA). The X-ray photoelectron spectroscopy (XPS) spectra of the GQDs were measured on a gold substrate using a $3000 \mathrm{~W} \mathrm{Al} \mathrm{K \alpha}$ as the microfocused monochromatic X-ray source (K-alpha, Thermo VG Scientific, Waltham, MA, USA).

\section{Results and Discussion}

\subsection{Morphological Features}

GQDs were prepared via the thermal decomposition of the $\mathrm{SiC}$ plates, as shown in Figure 1. The plates initially had flat surfaces, as shown in Figure 2a. However, when the plates were annealed at $1500{ }^{\circ} \mathrm{C}$ for $30 \mathrm{~min}$ in a vacuum furnace containing a gas mixture comprising $\mathrm{Ar}(96$ at.\%) and $\mathrm{H}(4$ at.\%), the morphology of the $\mathrm{SiC}$ surface was completely altered, dependent on the vacuum pressure, which was controlled by adjusting the flow rate of the gas mixture. At the vacuum pressure of 160 mTorr, irregularly shaped particulates of a few hundred nanometers in size were formed on the flat $\mathrm{SiC}$ surface, as can be seen in the FESEM image as shown in Figure S1b. Decreasing the pressure to $80 \mathrm{mTorr}$ led to the flat surface being converted into a bumpy structure with a surface roughness of a few micrometers, and on this bumpy surface, a large number of nanoparticles were created, as shown in Figure $2 \mathrm{~b}$ and Figure S1a. The nanoparticles were easily detached from the SiC plate by sonication in ethanol. The amount of GQDs detached from the $\mathrm{SiC}$ plate of $1 \mathrm{~cm} \times 1 \mathrm{~cm}$ was about $200 \mu \mathrm{g}$. The TEM image shows that the nanoparticles were monodispersed with a size of $2.58 \pm 0.31 \mathrm{~nm}$, as shown in Figure $2 \mathrm{c}$ and Figure S2).

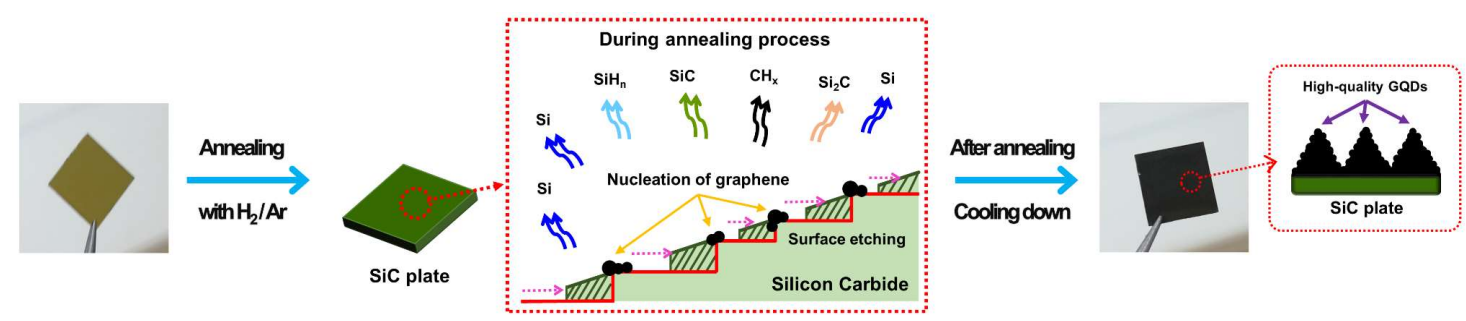

Figure 1. The schematic layout of the synthesis of high-quality graphene quantum dots (GQDs) by the hydrogen-assisted pyrolysis of silicon carbide (SiC).
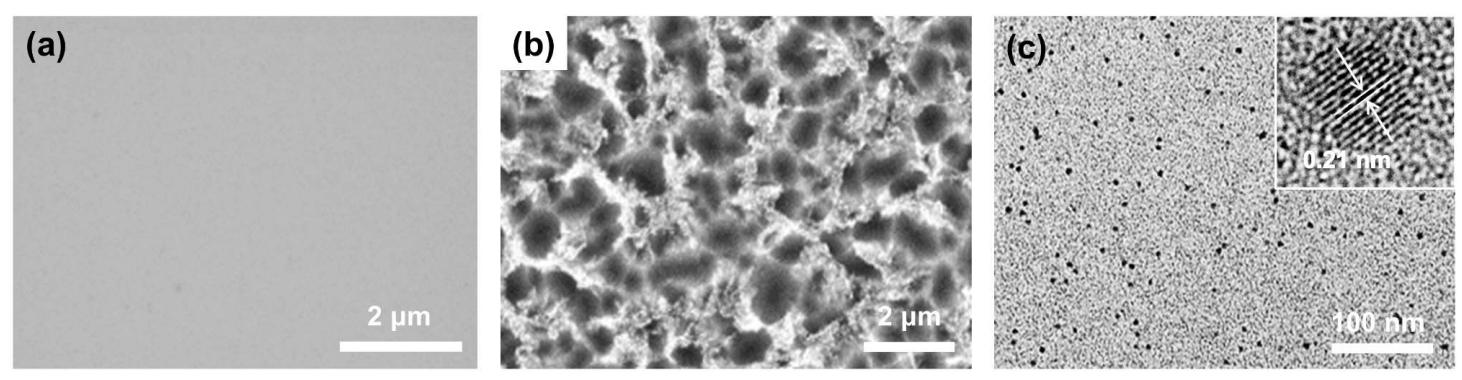

Figure 2. The field-emission scanning electron microscope (FESEM) image of (a) the pristine SiC plate and (b) the GQDs on the $\mathrm{SiC}$ plate after being annealed at $1500{ }^{\circ} \mathrm{C}$ on hydrogen etching gas. (c) The transmission electron microscope (TEM) image of the detached GQDs and the high-resolution transmission electron microscope (HRTEM) image of the GQDs with their lattice spacing.

\subsection{Structural Features}

The HRTEM image shows that the nanoparticles have a highly-ordered crystalline structure with a lattice spacing of $0.21 \mathrm{~nm}$, as shown in the inset of Figure 2c, which corresponds to that of the (100) planes of graphite [34]. In addition, the Raman spectra of the nanoparticles exhibit the D band at $1348 \mathrm{~cm}^{-1}$, the $\mathrm{G}$ band at $1582 \mathrm{~cm}^{-1}$ and the $2 \mathrm{D}$ band at $2701 \mathrm{~cm}^{-1}$, as shown in Figure $3 \mathrm{a}$. 
Both the TEM and Raman measurements support that the nanoparticles are indeed GQDs. The D to $G$ peak intensity ratio $\left(\mathrm{I}_{\mathrm{D}} / \mathrm{I}_{\mathrm{G}}\right)$ of the GQDs is 0.79 , and the $2 \mathrm{D}$ to $\mathrm{G}$ peak intensity ratio $\left(\mathrm{I}_{2 \mathrm{D}} / \mathrm{I}_{\mathrm{G}}\right)$ is 0.64 . Both values indicate a relatively high crystallinity considering that a large number of disordered edges exist on the GQDs [28]. It is notable that such a high 2D band, as seen in this study, has rarely been reported for previously synthesized GQDs $[16,35,36]$. The AFM image shows that the average thickness of the GQDs is $\sim 0.972 \mathrm{~nm}$, as shown in Figure $3 \mathrm{~b}$, indicating that the GQDs synthesized have few layers. The XPS survey spectrum, as shown in Figure S3, exhibits an intense C peak in the absence of any other peaks, such as that of oxygen, which indicates that the fabricated GQDs are high in purity. The high-resolution C1s XPS spectrum also supports that the GQDs are indeed highly pure. The spectrum exhibits only two peaks, corresponding to those of aromatic sp $\mathrm{sp}^{2}(284.4 \mathrm{eV})$ and sp $\mathrm{sp}^{3}(285 \mathrm{eV})$ carbon, with no peaks that are attributable to other elements, such as oxygen and nitrogen observed, as shown in Figure 3c, reflecting the high purity state of the fabricated GQDs. The FT-IR spectrum shows several peaks stemming from the aromatic $C=C\left(1550,1650 \mathrm{~cm}^{-1}\right)$ and $\mathrm{C}-\mathrm{H}\left(2854,2923 \mathrm{~cm}^{-1}\right)$ bonds, as shown in Figure 3d. The highly prevalent 2D band, the clear lattice spacing and the lack of impurities indicate that the synthesized GQDs are of high quality, with only a few defects on the basal plane. Additionally, the presence of $\mathrm{sp}^{3}$ carbon and $\mathrm{C}-\mathrm{H}$ bonds, supported by the obtained XPS and FT-IR spectra, suggests that the edges of GQDs are terminated with hydrogen. Consequently, from these analyses, we can conclude that high-quality GQDs with hydrogen-terminated edges are produced by annealing the $\mathrm{SiC}$ under low-vacuum environment containing $\mathrm{H}$ gas. The size of the GQDs can be controlled by adjusting the annealing temperature; the average size of the GQDs gradually increased from 2.58 to $5.20 \mathrm{~nm}$ when the temperature was decreased from $1500{ }^{\circ} \mathrm{C}$ to $1400{ }^{\circ} \mathrm{C}$ at a constant pressure of 80 mTorr, as shown in Figure 4.
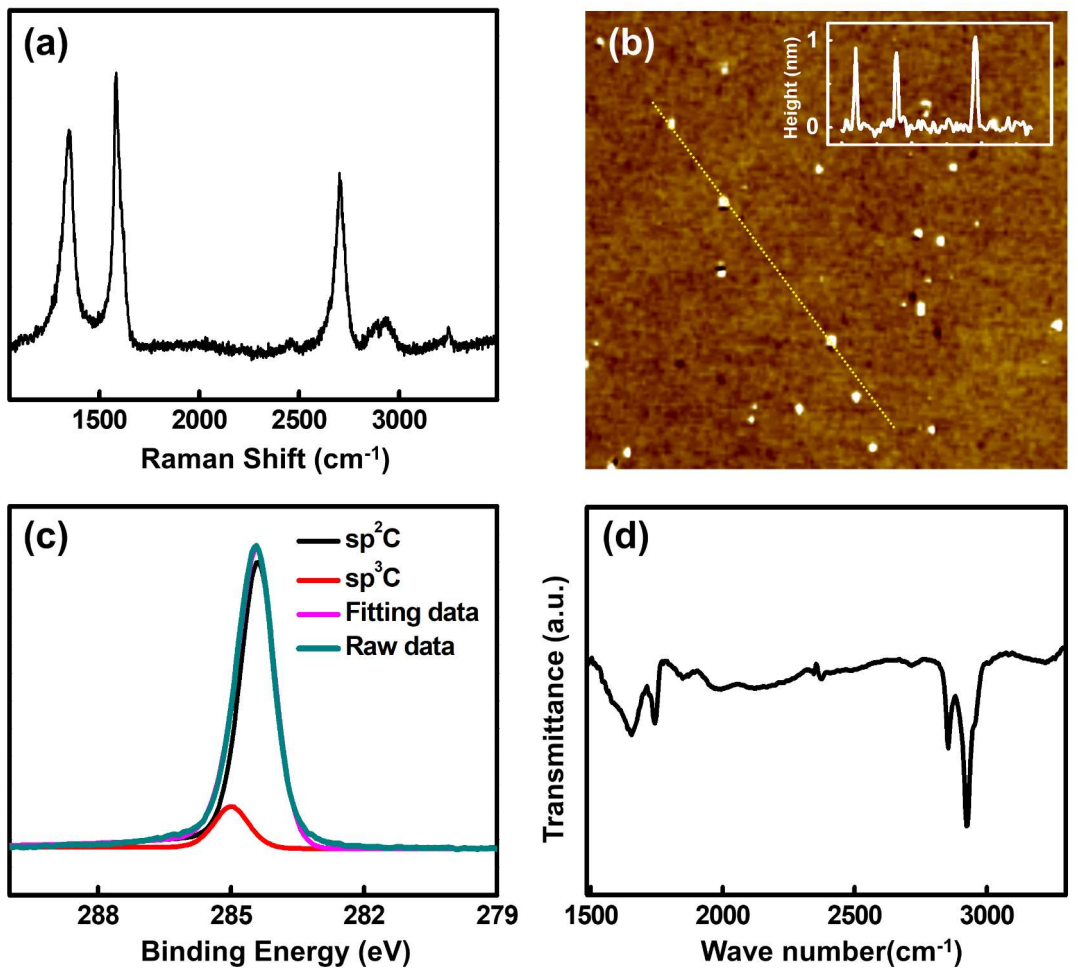

Figure 3. (a) The Raman spectra of the detached GQDs. (b) The atomic force microscope (AFM) image of the GQDs with the thickness graph of GQDs in yellow (the length of the yellow line inside the AFM image is $2.7 \mu \mathrm{m}$.). (c) The X-ray photoelectron spectroscopy (XPS) high-resolution C1s spectrum and (d) the Fourier transform infrared (FT-IR) results of the GQDs. 

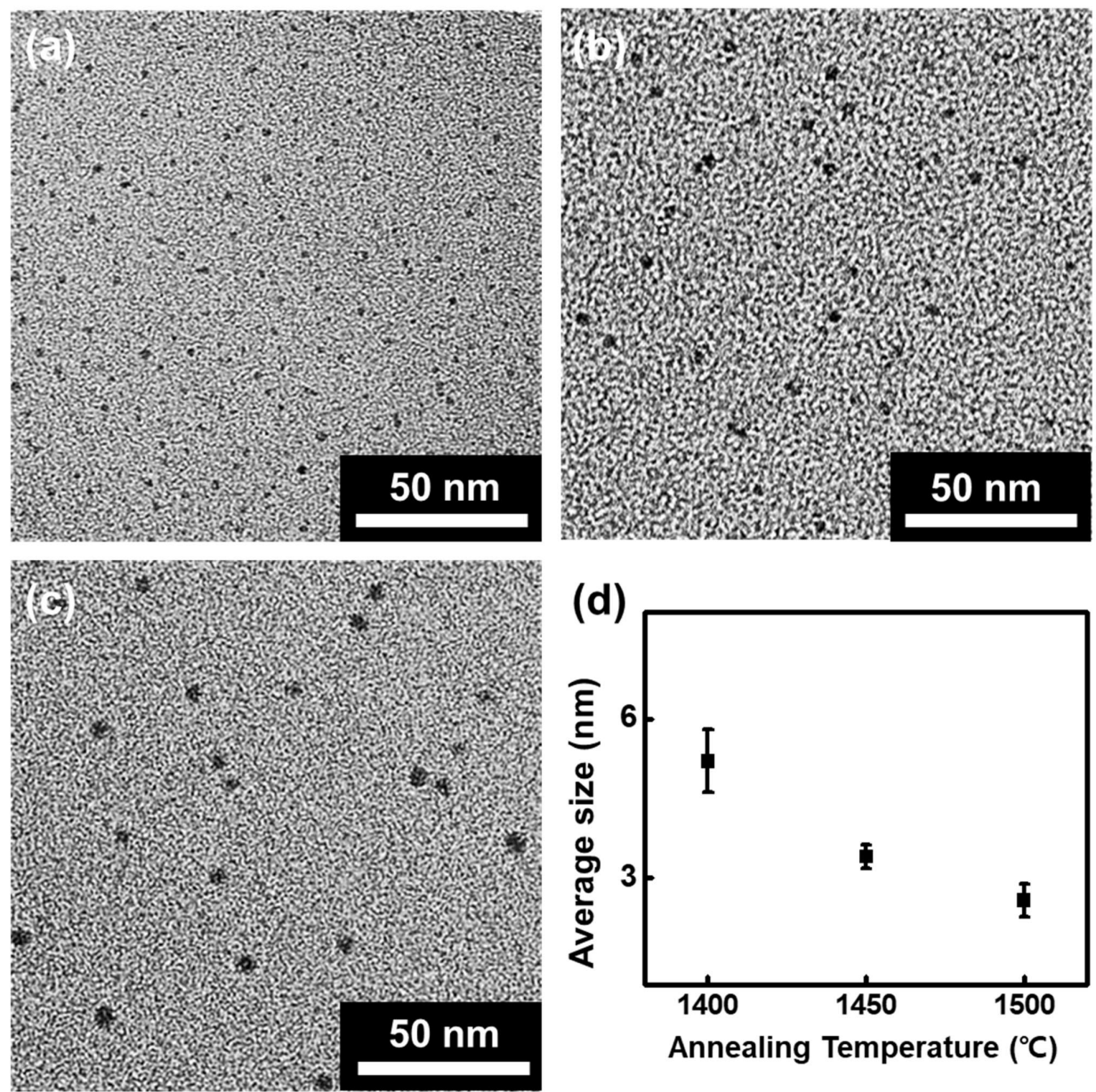

Figure 4. The HRTEM image of the GQDs fabricated on the $\mathrm{SiC}$ at a temperature of: (a) $1500{ }^{\circ} \mathrm{C}$, (b) $1450{ }^{\circ} \mathrm{C}$, (c) $1400{ }^{\circ} \mathrm{C}$, (d) The correlation graph between the annealing temperature and the average size of the GQDs.

\subsection{The Formation Mechanism of High-Quality GQDs}

The formation mechanism of the GQDs can be elaborated as follows and shown in Figure 1. The process of synthesizing the GQDs is very similar to that of EG on SiC. EG is generally synthesized by $\mathrm{H}$ etching of the $\mathrm{SiC}$ surface, followed by the thermal decomposition of the etched $\mathrm{SiC}$ [31]. H etching is carried out under atmospheric pressure in an $\mathrm{Ar}$ and $\mathrm{H}$ gas mixture, resulting in an array of steps to form on the $\mathrm{SiC}$ surface with heights less than $1.5 \mathrm{~nm}$ [37]. The step structure assists in the generation and growth of large and uniform graphene. However, in our study, $\mathrm{H}$ etching was not performed prior to the GQDs synthesis. Instead, the $\mathrm{H}$ etching and thermal decomposition were carried out simultaneously by annealing the $\mathrm{SiC}$ plates under low vacuum (mTorr range) while introducing $\mathrm{H}$ gas into the vacuum environment. The annealing environment significantly affects the morphologies of both the $\mathrm{SiC}$ surface and the synthesized graphene [31,32]. During annealing, $\mathrm{H}$ removes $\mathrm{Si}$ and $\mathrm{C}$ atoms from the $\mathrm{SiC}$ surface by forming volatile silicon hydrides and hydrocarbons. However, the removal rate of $\mathrm{C}$ is higher than that of $\mathrm{Si}$ due to hydrocarbon having a lower formation free energy than silicon hydride [38]. Additionally, annealing also induces sublimation of $\mathrm{Si}$ and $\mathrm{C}$ from the $\mathrm{SiC}$ surface with $\mathrm{Si}$ subliming faster than $\mathrm{C}$ due to the former having a lower vapor pressure than the latter [39]. If $\mathrm{SiC}$ is annealed in a vacuum environment containing $\mathrm{H}$, both $\mathrm{Si}$ and $\mathrm{C}$ atoms are more rapidly removed from the $\mathrm{SiC}$ surface, leading to faster etching when compared to annealing in an atmospheric pressure environment containing $\mathrm{H}$, or in a UHV environment without $\mathrm{H}$. This phenomenon is attributed to the fact that the decrease in vacuum pressure increases the Si sublimation rate, leading to a more rapid exposure of the $\mathrm{C}$ layer; the exposed $\mathrm{C}$ layer is then etched away by the $\mathrm{H}$. 
However, if the vacuum pressure is too low, only a very small amount of $\mathrm{H}$ gas can be present, resulting in the $\mathrm{C}$ atoms not being readily removed; in contrast, the $\mathrm{Si}$ atoms are being rapidly sublimated away. Consequently, if a $\mathrm{SiC}$ plate is annealed in the presence of $\mathrm{H}$ gas at a pressure that falls within a specific range, vigorous etching of the $\mathrm{SiC}$ occurs, leading to the formation of a very rough surface, like the one with the bumpy structure shown in Figure $2 b$.

Simultaneously with the etching process, graphene is synthesized on the bumpy SiC surface. C atoms are left on the $\mathrm{SiC}$ surface leading to graphene nucleation and growth due to the aforementioned annealing-induced Si sublimation [40]. However, the vigorous $\mathrm{H}$ etching process suppresses the growth of graphene, because $\mathrm{C}$ atoms are removed by the reactive $\mathrm{H}$ [41]. As a consequence, only small-sized GQDs are fabricated. $\mathrm{H}$ also reacts with the dangling bonds at the edges of the GQDs, resulting in $\mathrm{H}$-terminated GQDs [42]. Meanwhile, increasing the annealing temperature enhances the etching rate, resulting in even smaller GQDs, as shown in Figure 4 [43]. In contrast, increasing the vacuum pressure decreases the etching rate, leading to the formation of larger graphene crystallites and a less rough $\mathrm{SiC}$ surface. When the vacuum pressure is increased from 80 mTorr to 120 mTorr, the size of graphene crystallites increases from $2.58 \mathrm{~nm}$ to hundreds of $\mathrm{nm}$ and the surface roughness of $\mathrm{SiC}$ decreases from a few micrometers to less than $1 \mu \mathrm{m}$, as shown in Figure S1a. When the pressure is further increased to $160 \mathrm{mTorr}$, graphene with a size in the order of micrometers is produced on a flat pitless SiC surface, as shown in Figure S1b. The concentration of $\mathrm{H}$ in the H/Ar gas mixture can also affect the size of the resulting GQDs; however, the adjustment of the concentration, unless drastic, does not lead to a significant size variation, thus the effect of hydrogen concentration on the size of the GQDs was ignored.

\section{Conclusions}

In summary, we have presented a novel method for the fabrication of high-quality GQDs that involves the hydrogen-assisted pyrolysis of $\mathrm{SiC}$ in a vacuum. Annealing in a vacuum environment containing hydrogen causes a vigorous etching of $\mathrm{Si}$ and $\mathrm{C}$ atoms on the $\mathrm{SiC}$ surface, resulting in the formation of a bumpy surface and the production of hydrogen-terminated high-quality GQDs. The synthesized GQDs have a highly-ordered crystalline structure with almost no defects or impurities. The size of the GQDs can be altered by changing the operating conditions, such as the annealing temperature and the vacuum pressure. Thus, we believe that our proposed approach will be highly applicable in fields involving detectors and sensors.

Supplementary Materials: The following are available online at http://www.mdpi.com/2079-4991/10/2/277/s1, Figure S1: The FE-SEM image of the GQDs on the $\mathrm{SiC}$ plate after being annealed at $1500{ }^{\circ} \mathrm{C}$ with various operating hydrogen etching gas pressure. The operating pressure was (a) 120 mTorr (inset scale bar was $1 \mu \mathrm{m}$ ) and (b) 160 mTorr (inset scale bar was $1 \mu \mathrm{m}$ ); Figure S2: the size distribution of the fabricated GQDs; Figure S3: the X-ray photoelectron spectroscopy (XPS) survey spectrum of the fabricated high-quality GQDs.

Author Contributions: Conceptualization and methodology, N.E.L. and S.O.C.; formal analysis and investigation, N.E.L., S.Y.L., H.S.L. and S.H.Y.; writing — original draft preparation, writing-review and editing, all authors. All authors have read and agreed to the published version of the manuscript.

Funding: This work was funded by the National Research Foundation of Korea (NRF) grant funded by the Korea government, grant number NRF-2017M2A2A6A02070697.

Conflicts of Interest: The authors declare no conflict of interest.

\section{References}

1. Qu, D.; Zheng, M.; Du, P.; Zhou, Y.; Zhang, L.; Li, D.; Tan, H.; Zhao, Z.; Xie, Z.; Sun, Z. Highly luminescent S, $\mathrm{N}$ co-doped graphene quantum dots with broad visible absorption bands for visible light photocatalysts. Nanoscale 2013, 5, 12272-12277. [CrossRef]

2. Ju, J.; Chen, W. Synthesis of highly fluorescent nitrogen-doped graphene quantum dots for sensitive, label-free detection of Fe (III) in aqueous media. Biosens. Bioelectron. 2014, 58, 219-225. [CrossRef] [PubMed]

3. Qin, H.; Gong, T.; Jin, Y.; Cho, Y.; Shin, C.; Lee, C.; Kim, T. Near-UV-emitting graphene quantum dots from graphene hydrogels. Carbon 2015, 94, 181-188. [CrossRef] 
4. El Fatimy, A.; Myers-Ward, R.L.; Boyd, A.K.; Daniels, K.M.; Gaskill, D.K.; Barbara, P. Epitaxial graphene quantum dots for high-performance terahertz bolometers. Nat. Nanotechnol. 2016, 11, 335. [CrossRef]

5. Shen, J.; Zhu, Y.; Yang, X.; Li, C. Graphene quantum dots: Emergent nanolights for bioimaging, sensors, catalysis and photovoltaic devices. Chem. Commun. 2012, 48, 3686-3699. [CrossRef] [PubMed]

6. Zhu, S.; Zhang, J.; Qiao, C.; Tang, S.; Li, Y.; Yuan, W.; Li, B.; Tian, L.; Liu, F.; Hu, R. Strongly green-photoluminescent graphene quantum dots for bioimaging applications. Chem. Commun. 2011, 47, 6858-6860. [CrossRef] [PubMed]

7. Ananthanarayanan, A.; Wang, X.; Routh, P.; Sana, B.; Lim, S.; Kim, D.H.; Lim, K.H.; Li, J.; Chen, P. Facile synthesis of graphene quantum dots from $3 \mathrm{D}$ graphene and their application for $\mathrm{Fe} 3+$ sensing. Adv. Funct. Mater. 2014, 24, 3021-3026. [CrossRef]

8. Li, Y.; Hu, Y.; Zhao, Y.; Shi, G.; Deng, L.; Hou, Y.; Qu, L. An electrochemical avenue to green-luminescent graphene quantum dots as potential electron-acceptors for photovoltaics. Adv. Mater. 2011, 23, 776-780. [CrossRef]

9. Paulo, S.; Palomares, E.; Martinez-Ferrero, E. Graphene and carbon quantum dot-based materials in photovoltaic devices: From synthesis to applications. Nanomaterials 2016, 6, 157. [CrossRef]

10. Iannazzo, D.; Pistone, A.; Celesti, C.; Triolo, C.; Patané, S.; Giofré, S.V.; Romeo, R.; Ziccarelli, I.; Mancuso, R.; Gabriele, B. A Smart Nanovector for Cancer Targeted Drug Delivery Based on Graphene Quantum Dots. Nanomaterials 2019, 9, 282. [CrossRef]

11. Yao, X.; Niu, X.; Ma, K.; Huang, P.; Grothe, J.; Kaskel, S.; Zhu, Y. Graphene quantum dots-capped magnetic mesoporous silica nanoparticles as a multifunctional platform for controlled drug delivery, magnetic hyperthermia, and photothermal therapy. Small 2017, 13, 1602225. [CrossRef]

12. Konstantatos, G.; Badioli, M.; Gaudreau, L.; Osmond, J.; Bernechea, M.; De Arquer, F.P.G.; Gatti, F.; Koppens, F.H. Hybrid graphene-quantum dot phototransistors with ultrahigh gain. Nat. Nanotechnol. 2012, 7, 363. [CrossRef]

13. Cao, A.; Liu, Z.; Chu, S.; Wu, M.; Ye, Z.; Cai, Z.; Chang, Y.; Wang, S.; Gong, Q.; Liu, Y. A facile one-step method to produce graphene-CdS quantum dot nanocomposites as promising optoelectronic materials. Adv. Mater. 2010, 22, 103-106. [CrossRef] [PubMed]

14. Peng, J.; Gao, W.; Gupta, B.K.; Liu, Z.; Romero-Aburto, R.; Ge, L.; Song, L.; Alemany, L.B.; Zhan, X.; Gao, G.; et al. Graphene quantum dots derived from carbon fibers. Nano Lett. 2012, 12, 844-849. [CrossRef] [PubMed]

15. Liu, Q.; Zhang, J.; He, H.; Huang, G.; Xing, B.; Jia, J.; Zhang, C. Green preparation of high yield fluorescent graphene quantum dots from coal-tar-pitch by mild oxidation. Nanomaterials 2018, 8, 844. [CrossRef] [PubMed]

16. Zhang, M.; Bai, L.; Shang, W.; Xie, W.; Ma, H.; Fu, Y.; Fang, D.; Sun, H.; Fan, L.; Han, M. Facile synthesis of water-soluble, highly fluorescent graphene quantum dots as a robust biological label for stem cells. J. Mater. Chem. 2012, 22, 7461-7467. [CrossRef]

17. Pan, D.; Zhang, J.; Li, Z.; Wu, M. Hydrothermal route for cutting graphene sheets into blue-luminescent graphene quantum dots. Adv. Mater. 2010, 22, 734-738. [CrossRef] [PubMed]

18. Zhuo, S.; Shao, M.; Lee, S.-T. Upconversion and downconversion fluorescent graphene quantum dots: Ultrasonic preparation and photocatalysis. ACS Nano 2012, 6, 1059-1064. [CrossRef]

19. Shin, Y.; Lee, J.; Yang, J.; Park, J.; Lee, K.; Kim, S.; Park, Y.; Lee, H. Mass production of graphene quantum dots by one-pot synthesis directly from graphite in high yield. Small 2014, 10, 866-870. [CrossRef]

20. Lin, L.; Zhang, S. Creating high yield water soluble luminescent graphene quantum dots via exfoliating and disintegrating carbon nanotubes and graphite flakes. Chem. Commun. 2012, 48, 10177-10179. [CrossRef]

21. Song, S.H.; Jang, M.H.; Chung, J.; Jin, S.H.; Kim, B.H.; Hur, S.H.; Yoo, S.; Cho, Y.H.; Jeon, S. Highly Efficient Light-Emitting Diode of Graphene Quantum Dots Fabricated from Graphite Intercalation Compounds. Adv. Opt. Mater. 2014, 2, 1016-1023. [CrossRef]

22. Umrao, S.; Jang, M.-H.; Oh, J.-H.; Kim, G.; Sahoo, S.; Cho, Y.-H.; Srivastva, A.; Oh, I.-K. Microwave bottom-up route for size-tunable and switchable photoluminescent graphene quantum dots using acetylacetone: New platform for enzyme-free detection of hydrogen peroxide. Carbon 2015, 81, 514-524. [CrossRef]

23. Tang, L.; Ji, R.; Cao, X.; Lin, J.; Jiang, H.; Li, X.; Teng, K.S.; Luk, C.M.; Zeng, S.; Hao, J. Deep ultraviolet photoluminescence of water-soluble self-passivated graphene quantum dots. ACS Nano 2012, 6, 5102-5110. [CrossRef] [PubMed] 
24. Liu, R.; Wu, D.; Feng, X.; Müllen, K. Bottom-up fabrication of photoluminescent graphene quantum dots with uniform morphology. J. Am. Chem. Soc. 2011, 133, 15221-15223. [CrossRef]

25. Dong, Y.; Shao, J.; Chen, C.; Li, H.; Wang, R.; Chi, Y.; Lin, X.; Chen, G. Blue luminescent graphene quantum dots and graphene oxide prepared by tuning the carbonization degree of citric acid. Carbon 2012, 50, 4738-4743. [CrossRef]

26. Lu, J.; Yeo, P.S.E.; Gan, C.K.; Wu, P.; Loh, K.P. Transforming C 60 molecules into graphene quantum dots. Nat. Nanotechnol. 2011, 6, 247. [CrossRef]

27. Wu, X.; Tian, F.; Wang, W.; Chen, J.; Wu, M.; Zhao, J.X. Fabrication of highly fluorescent graphene quantum dots using L-glutamic acid for in vitro/in vivo imaging and sensing. J. Mater. Chem. C 2013, 1, 4676-4684. [CrossRef]

28. Liu, D.; Chen, X.; Hu, Y.; Sun, T.; Song, Z.; Zheng, Y.; Cao, Y.; Cai, Z.; Cao, M.; Peng, L. Raman enhancement on ultra-clean graphene quantum dots produced by quasi-equilibrium plasma-enhanced chemical vapor deposition. Nat. Commun. 2018, 9, 193. [CrossRef]

29. Jernigan, G.G.; VanMil, B.L.; Tedesco, J.L.; Tischler, J.G.; Glaser, E.R.; Davidson, A., III; Campbell, P.M.; Gaskill, D.K. Comparison of epitaxial graphene on Si-face and C-face $4 \mathrm{H} \mathrm{SiC}$ formed by ultrahigh vacuum and RF furnace production. Nano Lett. 2009, 9, 2605-2609. [CrossRef]

30. Hupalo, M.; Conrad, E.; Tringides, M. Growth mechanism for epitaxial graphene on vicinal 6 H-SiC (0001) surfaces: A scanning tunneling microscopy study. Phys. Rev. B 2009, 80, 041401. [CrossRef]

31. Emtsev, K.V.; Bostwick, A.; Horn, K.; Jobst, J.; Kellogg, G.L.; Ley, L.; McChesney, J.L.; Ohta, T.; Reshanov, S.A.; Röhrl, J. Towards wafer-size graphene layers by atmospheric pressure graphitization of silicon carbide. Nat. Mater. 2009, 8, 203. [CrossRef] [PubMed]

32. Boeckl, J.; Mitchel, W.; Clarke, E.; Barbosa, R.L.; Lu, W.J. Structural Evaluation of Graphene/SiC (0001) Grown in Atmospheric Pressure. In Materials Science Forum; Trans Tech Publications Ltd.: Stafa, Zurich, Switzerland, 2010; Volume 645, pp. 573-576.

33. Huang, Q.; Kim, J.J.; Ali, G.; Cho, S.O. Width-tunable graphene nanoribbons on a SiC substrate with a controlled step height. Adv. Mater. 2013, 25, 1144-1148. [CrossRef] [PubMed]

34. Ding, Z.; Li, F.; Wen, J.; Wang, X.; Sun, R. Gram-scale synthesis of single-crystalline graphene quantum dots derived from lignin biomass. Green Chem. 2018, 20, 1383-1390. [CrossRef]

35. Zhou, X.; Guo, S.; Zhong, P.; Xie, Y.; Li, Z.; Ma, X. Large scale production of graphene quantum dots through the reaction of graphene oxide with sodium hypochlorite. RSC Adv. 2016, 6, 54644-54648. [CrossRef]

36. Huang, Z.; Shen, Y.; Li, Y.; Zheng, W.; Xue, Y.; Qin, C.; Zhang, B.; Hao, J.; Feng, W. Facile synthesis of analogous graphene quantum dots with sp 2 hybridized carbon atom dominant structures and their photovoltaic application. Nanoscale 2014, 6, 13043-13052. [CrossRef]

37. Nakajima, A.; Yokoya, H.; Furukawa, Y.; Yonezu, H. Step control of vicinal $6 \mathrm{H}-\mathrm{SiC}(0001)$ surface by H 2 etching. J. Appl. Phys. 2005, 97, 104919. [CrossRef]

38. Kumagawa, M.; Kuwabara, H.; Yamada, S. Hydrogen etching of silicon carbide. Jpn. J. Appl. Phys. 1969, 8, 421. [CrossRef]

39. De Heer, W.A.; Berger, C.; Ruan, M.; Sprinkle, M.; Li, X.; Hu, Y.; Zhang, B.; Hankinson, J.; Conrad, E. Large area and structured epitaxial graphene produced by confinement controlled sublimation of silicon carbide. Proc. Natl. Acad. Sci. USA 2011, 108, 16900-16905. [CrossRef]

40. Zhang, R.; Dong, Y.; Kong, W.; Han, W.; Tan, P.; Liao, Z.; Wu, X.; Yu, D. Growth of large domain epitaxial graphene on the C-face of SiC. J. Appl. Phys. 2012, 112, 104307. [CrossRef]

41. Cai, T.; Jia, Z.; Yan, B.; Yu, D.; Wu, X. Hydrogen assisted growth of high quality epitaxial graphene on the C-face of 4H-SiC. Appl. Phys. Lett. 2015, 106, 013106. [CrossRef]

42. Li, X. Epitaxial graphene films on SiC: Growth, Characterization, and Devices. Ph.D. Thesis, Georgia Institute of Technology, Atlanta, GA, USA, 2008.

43. Nyakiti, L.; Wheeler, V.; Garces, N.; Myers-Ward, R.; Eddy, C.; Gaskill, D. Enabling graphene-based technologies: Toward wafer-scale production of epitaxial graphene. MRS Bull. 2012, 37, 1149-1157. [CrossRef]

(C) 2020 by the authors. Licensee MDPI, Basel, Switzerland. This article is an open access article distributed under the terms and conditions of the Creative Commons Attribution (CC BY) license (http://creativecommons.org/licenses/by/4.0/). 